\title{
DESENVOLVIMENTO E VALIDAÇÃo DE MÉTODO ANALÍTICO PARA DETERMINAÇÃO SIMULTÂNEA DE LAMIVUDINA, ZIDOVUDINA E NEVIRAPINA EM COMPRIMIDOS DOSE-FIXA COMBINADA POR CROMA- TOGRAFIA LÍQUIDA DE ALTA EFICIÊNCIA
}

\author{
Zênia Maria Maciel Lavra e Pedro José Rolim Neto* \\ Departamento de Ciências Farmacêuticas, Faculdade de Ciências Farmacêuticas, Universidade Federal de Pernambuco, \\ Av. Prof. Arthur de Sá, s/n, Cidade Universitária, 50740-521 Recife - PE, Brasil \\ Rosali Maria Ferreira da Silva e Flávia Patrícia Morais de Medeiros \\ Laboratório Farmacêutico do Estado de Pernambuco, Largo de Dois Irmãos, 1117, 52171-010 Recife - PE, Brasil
}

Recebido em 8/12/06; aceito em 11/10/07; publicado na web em 9/4/08

\begin{abstract}
DEVELOPMENT AND VALIDATION OF AN ANALYTICAL METHOD FOR SIMULTANEOUS DETERMINATION OF FIXEDDOSE COMBINATION TABLETS OF LAMIVUDINE, ZIDOVUDINE AND NEVIRAPINE BY HIGH PERFORMANCE LIQUID CHROMATOGRAPHY. An analytical method has been developed and validated for the quantitation of lamivudine, zidovudine and nevirapine in the fixed-dose combination film-coated tablet by high performance liquid chromatography, in accordance with RE No. 899/2003, National Sanitary Surveillance Agency. It was based on an isocratic elution system with a potassium phosphate buffer $\mathrm{pH}$ 3.0: acetonitrile $(60: 40 \mathrm{v} / \mathrm{v})$ mobile phase, $\mathrm{C} 18,250$ x $46 \mathrm{~mm}$ column, $10 \mu \mathrm{m}$ particle size, $\lambda 270 \mathrm{~nm}$. The statistically evaluated results have shown that the method is specific, precise, accurate, and robust, ensuring the analytical safety of 3TC, AZT and NVP determination, which emerges as a new therapeutic alternative for antiretroviral treatment.
\end{abstract}

Keywords: fixed-dose combination; validation; HPLC.

\section{INTRODUÇÃO}

A introdução da terapia combinada tem reduzido a morbidade e mortalidade de pacientes infectados pelo vírus da imuno-deficiência humana (HIV). Fármacos de várias classes farmacológicas e com mecanismos de ação em diferentes etapas da replicação viral têm sido associados na forma de dose-fixa-combinada (DFC). Um dos mais potentes regimes terapêuticos inclui dois inibidores da transcriptase reversa análogos de nucleosídeos (ITRN), a lamivudina (3TC) e a zidovudina (AZT) e um não análogo (ITRNN), a nevirapina (NVP). ${ }^{1}$

A produção de comprimidos revestidos DFC, como nova alternativa terapêutica, exige o desenvolvimento e a validação de um método analítico que atenda às especificações dos órgãos reguladores, haja vista a ausência de métodos publicados em compêndios oficiais para quantificação destes fármacos associados.

A validação de um método assegura a especificidade, exatidão e precisão de um ensaio analítico e estima a estabilidade do analito durante a estocagem e manipulação, ${ }^{2}$ tendo como objetivo garantir que o procedimento analítico forneça resultados reprodutíveis e confiáveis, que sejam adequados aos fins para os quais tenha sido planejado. $^{3}$

Técnicas de separação, como a cromatografia líquida de alta eficiência (CLAE), destacam-se na química analítica pela capacidade de realizar análises quali-quantitativas em amostras farmacêuticas, ${ }^{4}$ sendo freqüentemente utilizadas para determinação de fármacos em formulações farmacêuticas, especialmente nas que contêm mais de um constituinte ativo.

Métodos publicados em artigos científicos e compêndios oficiais foram tomados como referência no desenvolvimento deste aqui descrito. Keneey et al. ${ }^{5}$ publicaram um método cromatográfico para quantificação de AZT + 3TC em plasma humano, tendo como

*e-mail: pedro.rolim@ @esquisador.cnpq.br fase estacionária uma coluna $\mathrm{C}_{18}$ e como eluente uma mistura de água e acetonitrila. Rodriguez et al., ${ }^{6}$ também utilizaram uma coluna $\mathrm{C}_{18}$ e como eluente, acetonitrila e metanol. Doerge et al., ${ }^{7}$ por sua vez, variaram apenas a fase móvel para acetonitrila e ácido fosfórico, sendo considerado, portanto que estes dois últimos métodos apresentaram maior custo que o descrito por Kenney. ${ }^{5}$ Pesquisas na literatura revelaram a determinação individual da nevirapina em fluidos biológicos por cromatografia gasosa, CLAE associada a detector ultravioleta, CLAE com extração de fase sólida ou associada à espectrofotometria de massa. Mahadik et al. ${ }^{8}$ publicaram um método por HTPLC (cromatografia em camada delgada de alta performance) no qual foi utilizado um sistema solvente constituído por tolueno, tetracloreto de carbono, metanol, acetona e amônia. Este mesmo fármaco também tem sua análise isolada publicada na Farmacopéia Brasileira, utilizando uma fase móvel constituída de tampão fosfato e acetonitrila, apresentando assim um método mais simples e de custo mais acessível.

Este estudo descreve o desenvolvimento e a validação de um método analítico por cromatografia líquida de alta eficiência para detecção e quantificação simultânea de lamivudina, zidovudina e nevirapina em comprimidos revestidos DFC, atendendo às exigências do guia para validação de métodos analíticos publicado na Resolução RE no 899/2003, da Agência Nacional de Vigilância Sanitária. ${ }^{9}$

\section{PARTE EXPERIMENTAL}

\section{Materiais}

\section{Medicamento}

Comprimidos revestidos desenvolvidos pelo Laboratório Farmacêutico do Estado de Pernambuco - LAFEPE, contendo $150 \mathrm{mg}$ de lamivudina, $300 \mathrm{mg}$ de zidovudina e $200 \mathrm{mg}$ de nevirapina. 


\section{Padrões de trabalho}

Para o desenvolvimento e validação do método analítico de doseamento do comprimido revestido foram utilizados padrões de trabalho de lamivudina (Northeast ${ }^{\circledR}$ lote 00019 - teor 100,47\%), zidovudina (Ítaca ${ }^{\circledR}$ lote HVZ0210304 - teor 100,0\%) e nevirapina (Xiamem Mchem ${ }^{\circledR}$ lote 050501 - teor 98,32\%).

\section{Excipientes}

Celulose microcristalina 101 (Valdequímica $^{\circledR}$ ), amido de milho $\left(\right.$ Cargill $\left.^{\circledR}\right)$, glicolato de amido sódico $\left(\right.$ Blanver $\left.^{\circledR}\right)$, dióxido de silício coloidal (Degussa ${ }^{\circledR}$ ), polivinilpirrolidona $\left(\right.$ Forlab $^{\circledR}$ ), estearato de magnésio (Labsynth ${ }^{\circledR}$ ) e constituintes do revestimento: polietilenoglicol (PEG), álcool polivinílico (PVA), talco e dióxido de titânio $\left(\right.$ Colorcon $\left.^{\circledR}\right)$.

\section{Reagentes}

Acetonitrila (J. T. Baker ${ }^{\circledR}$ ), fosfato de potássio monobásico $\left(\right.$ Nuclear $\left.^{\circledR}\right)$, ácido fosfórico $85 \%$ (Merck ${ }^{\circledR}$ ) e água ultra-pura obtida por sistema Milli-q-Plus (Millipore Corporation ${ }^{\circledR}$ ).

\section{Equipamentos e condições cromatográficas}

Cromatógrafo líquido de alta eficiência Shimadzu ${ }^{\circledR}$ equipado com bomba binária LC - 10 ADVP, auto-injetor SIL - 10 ADVP, detector UV SPD - 10 AVP, controlador de sistema SCL - 10 AVP e forno para coluna CTO - 10 ASVP. As colunas utilizadas neste estudo foram: coluna $C_{8}$ (Waters $^{\circledR}$ ), $250 \times 4,6 \mathrm{~mm}$, partícula $10 \mu \mathrm{m}$

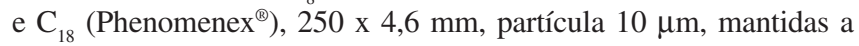
$30{ }^{\circ} \mathrm{C}$. A fase móvel utilizada foi tampão fosfato $\mathrm{pH} 3,0$ e acetonitrila grau HPLC.

Foram utilizadas vidrarias $\left(\right.$ Pyrex $^{\circledR}$ ) certificadas por lote e equipamentos previamente qualificados e certificados: sistema de purificação de água Milli-q-Plus (Millipore Corporation ${ }^{\circledR}$ ), aparelho de ultrassom (Ultrasonic Cleaner Unique ${ }^{\circledR}$ ), balança analítica $\left(\right.$ Mettler $^{\circledR}$ ), unidades filtrantes de 0,45 $\mu \mathrm{m}$ (Millex Millipore ${ }^{\circledR}$ ), papel de filtro faixa preta (Schleicher \& Scheuell $^{\circledR}$ ) e espectrofotômetro UV (Cary 50 Varian $\left.^{\circledR}\right)$.

\section{Método}

\section{Desenvolvimento do método analítico}

Tendo em vista que os três fármacos isolados já apresentam monografias descritas na Farmacopéia Brasileira, ${ }^{10}$ foram quantificados por seus métodos cromatográficos específicos nos comprimentos de onda de $254 \mathrm{~nm}$ para AZT, $277 \mathrm{~nm}$ para 3TC e $237 \mathrm{~nm}$ para NVP. O desenvolvimento do método teve início com a realização de uma varredura espectrofotométrica na região do UV visível, numa faixa de 200 a $800 \mathrm{~nm}$, do padrão misto contendo os três fármacos, objetivando-se identificar em qual comprimento de onda os três fármacos associados apresentavam valores de absorvâncias máximos.

Após realização de pesquisas referente a métodos de análises para quantificação de antiretrovirais, já descritos em farmacopéias $^{10,11}$ e em artigos científicos publicados, ${ }^{2,5-8}$ foram testadas variações, avaliando-se os seguintes parâmetros: fase estacionária $\left(\mathrm{C}_{8}\right.$ e $\left.\mathrm{C}_{18}\right)$; fase móvel, modificando-se as proporções do tampão fosfato de potássio monobásico $\mathrm{pH} 3,0\left(\mathrm{~K}_{2} \mathrm{HPO}_{4}\right)$ e acetonitrila $(\mathrm{ACN})$; vazão (1,0 e 1,5 $\mathrm{mL} / \mathrm{min})$ e volume de injeção (10,0 e 20,0 $\mu \mathrm{L})$.

A partir dos cromatogramas obtidos, avaliou-se a adequação do sistema cromatográfico através dos parâmetros: fator de capacidade, número de pratos, fator de assimetria e resolução entre os picos.

\section{Preparação da solução tampão fosfato 0,05 M pH 3,0}

A solução tampão foi preparada dissolvendo-se 7,09 $\mathrm{g}$ de fosfato de potássio monobásico em água ultrapura em $1000 \mathrm{~mL}$. O ajuste do $\mathrm{pH}$ foi realizado com ácido fosfórico $85 \%$.

\section{Preparação das amostras}

Os comprimidos revestidos DFC foram pesados, triturados e pulverizados. O equivalente a 37,5 mg de 3TC, $75 \mathrm{mg}$ de AZT e 50 mg de NVP foi pesado analiticamente, transferido para balão volumétrico de $100 \mathrm{~mL}$, diluído em fase móvel e sonicado por 20 minutos. As amostras foram aferidas e filtradas em papel de filtro faixa-preta. Do filtrado, retirou-se alíquota volumétrica e diluiu-se com fase móvel até obtenção da concentração final de 45, 90 e 60 $\mu \mathrm{g} / \mathrm{mL}$ de $3 \mathrm{TC}$, AZT e NVP, respectivamente. As soluções obtidas foram filtradas em unidades filtrantes de $0,45 \mu \mathrm{m}$ e analisadas por CLAE. Foram preparadas amostras em quintuplicatas.

\section{Preparação da curva controle}

As curvas controle foram preparadas diariamente a partir de diluições de uma solução estoque do padrão misto em fase móvel (375 $\mu \mathrm{g} / \mathrm{mL}$ de $3 \mathrm{TC}, 750 \mu \mathrm{g} / \mathrm{mL}$ de AZT e $500 \mu \mathrm{g} / \mathrm{mL}$ de NVP), obtendo-se concentrações de 30, 45 e $75 \mu \mathrm{g} / \mathrm{mL}$ para 3TC, 60, 90 e $150 \mu \mathrm{g} / \mathrm{mL}$ para $\mathrm{AZT}$ e 40,60 e $100 \mu \mathrm{g} / \mathrm{mL}$ para NVP, referentes às concentrações mínima, média e máxima.

\section{Validação do método analítico}

\section{Condições cromatográficas}

O método de separação cromatográfica desenvolvido capaz de quantificar os três fármacos presentes nos comprimidos revestidos foi alcançado com sistema de eluição isocrático, em coluna de fase reversa $\mathrm{C}_{18}, 250 \times 4,6 \mathrm{~mm}$, partícula $10 \mu \mathrm{m}$, a temperatura de 30 ${ }^{\circ} \mathrm{C}$. A fase móvel foi constituída de $60 \%$ de tampão fosfato de potássio 0,05 M pH 3,0 e 40\% de acetonitrila, com vazão de 1,0 mL/ min e volume de injeção de $20 \mu \mathrm{L}$. O comprimento de onda selecionado foi $270 \mathrm{~nm}$.

\section{Parâmetros avaliados}

O método proposto foi validado seguindo os parâmetros de linearidade, robustez, faixa de variação, precisão, exatidão, especificidade e limites de detecção e quantificação de cada princípio ativo, especificados na Resolução RE n ${ }^{\circ}$ 899/2003. ${ }^{9}$

A linearidade do método foi verificada a partir da análise de três curvas autênticas do padrão misto nas concentrações de 30; 37,$5 ; 45 ; 60$ e $75 \mu \mathrm{g} / \mathrm{mL}$ para $3 \mathrm{TC} ; 60 ; 75 ; 90 ; 120$ e $150 \mu \mathrm{g} / \mathrm{mL}$ para AZT e 40; 50; 60; 80 e $100 \mu \mathrm{g} / \mathrm{mL}$ para NVP. Os resultados obtidos foram tratados estatisticamente, por cálculo de regressão linear pelo método dos mínimos quadrados. O intervalo de variação testado foi entre 66 e $166 \%$ da concentração média dos três fármacos.

No parâmetro robustez foi analisada a possível influência de pequenas variações ocasionadas pela alteração na proporção da composição da fase móvel, na vazão, na temperatura do forno, no tempo de sonicação para preparação das amostras e em diferentes lotes da coluna utilizada como fase estacionária. Na variação da proporção da fase móvel, foram realizadas análises com tampão fosfato de potássio monobásico $\mathrm{pH} 3,0$ :acetonitrila nas proporções de 62:38 (v/v); 60:40 (v/v); e 58:42 (v/v). Em relação à vazão, a variação analisada foi de 0,$99 ; 1,00$ e $1,01 \mathrm{~mL} / \mathrm{min}$. A variação do tempo de sonicação para preparação das amostras foi de 15, 20 e 25 min. Para a temperatura do forno, foram avaliadas as variações de 28,30 e $32{ }^{\circ} \mathrm{C}$.

A especificidade e seletividade do método foi determinada pela 
análise do placebo dos comprimidos revestidos contendo amido, celulose microscristalina 101, polivinilpirrolidona, glicolato de amido sódico, dióxido de silício coloidal e estearato de magnésio, componentes do núcleo, PEG, álcool polivinílico, talco e dióxido de titânio, componentes do revestimento.

A precisão foi avaliada em dois níveis: repetitividade (precisão intra-corrida) e precisão intermediária (precisão inter-corridas). Para a repetitividade, replicatas de 6 determinações a $100 \%$ da concentração teste dos fármacos associados foram analisadas. Já para precisão intermediária, 5 replicatas foram analisadas em dias diferentes e por analistas diferentes.

Para avaliar a exatidão do método, amostras em concentrações conhecidas equivalentes a 66, 100 e $166 \%$ da concentração teórica analisada para cada fármaco foram testadas, as quais correspondem às concentrações mínima, média e máxima, respectivamente.

Os limites de detecção (LD) e quantificação (LQ) foram estimados de acordo com as equações $\mathrm{LD}=\mathrm{DP} \times 3 / \mathrm{IC}$ e $\mathrm{LQ}=\mathrm{DP} \times 10 /$ IC, onde DP é o desvio padrão dos coeficientes lineares obtido com as três curvas de linearidade e IC é a média dos coeficientes angulares das respectivas curvas, segundo a RE 899/2003 (ANVISA). ${ }^{9}$

\section{RESULTADOS E DISCUSSÃO}

\section{Desenvolvimento do método analítico}

As condições para o método cromatográfico foram primeiramente estabelecidas com o padrão misto de 3TC, AZT e NVP e, após otimização dos parâmetros, foram aplicadas para o doseamento do comprimido revestido DFC.

A varredura espectrofotométrica (Figura 1) realizada para verificação do comprimento de onda adequado demonstrou que a associação de fármacos apresentava absorvância adequada em 270 $\mathrm{nm}$, sendo confirmado por análise cromatográfica em detector de varredura por fotodiodo e pela quantificação comparativa dos fármacos isolados nos métodos farmacopêicos.

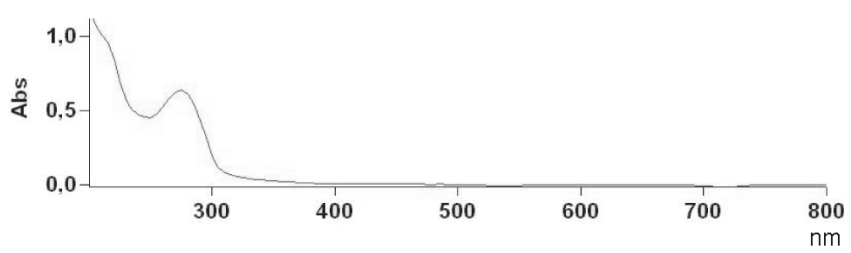

Figura 1. Varredura espectrofotométrica no UV- visível do padrão misto contendo 3TC, AZT e NVP
Por apresentar os três picos simétricos, com boa resolução entre eles e áreas bem definidas, a fase estacionária escolhida para o doseamento foi a coluna $\mathrm{C}_{18}\left(\right.$ Phenomenex $\left.^{\circledR}\right)$.

Sob as condições experimentais verificadas (Tabela 1) o método 2 foi o escolhido por apresentar melhor resolução entre os picos, condições ideais para conservação da coluna e tempos de retenção de 2,4 min para 3TC; 3,4 min para AZT e 4,8 min para NVP, adequado a rotina de análise para aprovação ou liberação do produto na indústria farmacêutica. A temperatura selecionada foi de $30{ }^{\circ} \mathrm{C}$ por ser percebida durante as análises como a que apresenta maior facilidade de estabilização para o forno do cromatógrafo. O volume de injeção e a vazão selecionados foram $20 \mu \mathrm{L}$ e $1,0 \mathrm{~mL} /$ min, respectivamente. $\mathrm{O}$ cromatograma é apresentado na Figura 2.

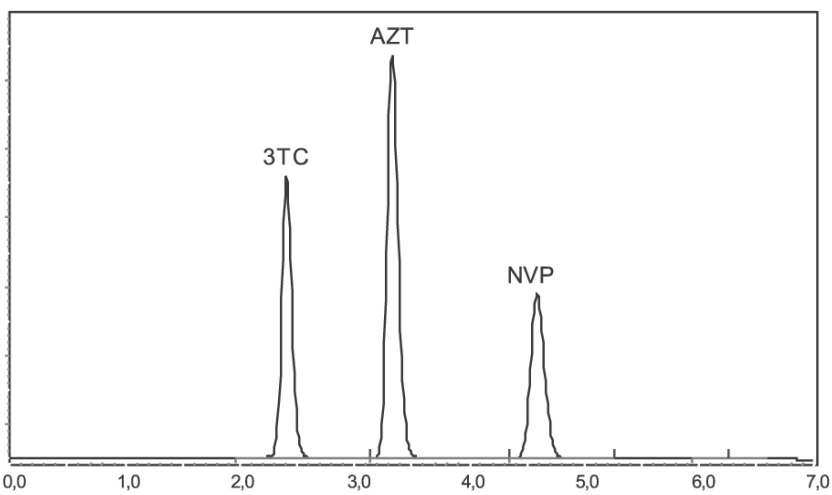

Figura 2. Cromatograma referente ao método analítico para quantificação de lamivudina (45 $\mu \mathrm{g} / \mathrm{mL})$, zidovudina (90 $\mu \mathrm{g} / \mathrm{mL}$ ) e nevirapina (60 $\mu \mathrm{g} / \mathrm{mL}$ ) em comprimido revestido dose-fixa-combinada, utilizando coluna $C_{18}$, fase móvel tampão fosfato pH 3,0:acetonitrila (60:40), fluxo 1,0 mL/min e volume de injeção $20 \mu \mathrm{L}$

A performance do sistema cromatográfico escolhido foi avaliada de acordo com os parâmetros: fator de capacidade, resolução entre os picos, fator de assimetria e número de pratos. A resolução entre os picos mede a qualidade da separação entre eles: quanto mais distantes, melhor a separação e mais segura é a quantificação. Os valores da resolução entre os picos 3TC e AZT foi de 5,46 e entre AZT e NVP 6,70 sendo superiores a 2,00, indicando separação eficaz entre os mesmos. O fator de assimetria obtido foi de 1,30 para 3TC; 1,24 para AZT e 1,19 para NVP, apresentando, portanto, valores inferiores a 1,5 , descrito na literatura como aceitável para amostras de interesse. ${ }^{12} \mathrm{O}$ número de pratos diz respeito à eficiência da coluna, devendo ser superior a $2000 .^{4,13}$ Neste método, os resultados foram 3330,56; 4927,21; 5828,60 para 3TC, AZT e NVP, respectivamente.

Tabela 1. Resultados dos testes realizados durante o desenvolvimento do método analítico proposto para quantificação de 3TC, AZT e NVP

\begin{tabular}{|c|c|c|c|c|c|c|}
\hline Parâmetros & Método 1 & Método 2 & Método 3 & Método 4 & Método 5 & Método 6 \\
\hline Fase móvel & $60: 40$ & $60: 40$ & $25: 75$ & $75: 25$ & $60: 40$ & $60: 40$ \\
\hline Fase estacionária & C8 & $\mathrm{C} 18$ & $\mathrm{C} 18$ & C18 & $\mathrm{C} 18$ & $\mathrm{C} 18$ \\
\hline Fluxo (mL/min) & 1,0 & 1,0 & 1,0 & 1,0 & 1,0 & 1,5 \\
\hline Tempo $\quad 3 \mathrm{TC}$ & 2,4 & 2,4 & 2,4 & 2,8 & 2,3 & 1,6 \\
\hline de retenção AZT & 3,4 & 3,4 & 2,7 & 5,0 & 2,9 & 1,9 \\
\hline$(\min ) \quad$ NVP & 4,6 & 4,8 & 3,1 & 10,1 & 3,4 & 2,3 \\
\hline Volume de injeção $(\mu \mathrm{L})$ & 20 & 20 & 20 & 20 & 10 & 20 \\
\hline Resultado & $\begin{array}{l}\text { Picos com } \\
\text { assimetria } \\
\text { caudal }\end{array}$ & $\begin{array}{l}\text { Boa resolução } \\
\text { entre os pico e } \\
\text { áreas reprodutíveis }\end{array}$ & $\begin{array}{l}\text { Não houve } \\
\text { separação } \\
\text { dos picos }\end{array}$ & $\begin{array}{l}\text { Tempo de } \\
\text { retenção alto para } \\
\text { rotina de análise }\end{array}$ & $\begin{array}{l}\text { Áreas não } \\
\text { reprodutíveis }\end{array}$ & $\begin{array}{c}\text { Picos muito } \\
\text { próximos }\end{array}$ \\
\hline
\end{tabular}




\section{Validação do método analítico}

Os resultados obtidos da avaliação dos parâmetros foram tratados estatisticamente por Análise de Variância (ANOVA) one-way e teste t de Student, ${ }^{13}$ com nível de significância de $95 \%$.

Robustez

Um método robusto tem a habilidade de fornecer resultados inalterados quando sujeito a pequenas mudanças. ${ }^{14}$ Para todas as modificações analisadas na robustez, proporção da fase móvel, variação da vazão, tempo de sonicação da amostra, variação da temperatura do forno e número de lote da fabricação da coluna, os resultados obtidos apresentaram desvio padrão relativo inferior a $2,0 \%$, a partir de amostras analisadas em quintuplicata. Pela análise estatística dos resultados, foi verificado que os valores obtidos para os $F$ calculados foram inferiores ao do $F$ tabelado, determinando com $95 \%$ de confiança que o método é robusto para estas variáveis testadas (Tabela 2).

Lineridade e intervalo de variação

A linearidade de um método demonstra que os resultados obti- dos são diretamente proporcionais à concentração do fármaco na amostra, dentro de um intervalo especificado. ${ }^{9}$ As áreas obtidas no intervalo de variação analisado demonstraram que não há falta de ajuste no modelo proposto, visto que os resíduos não apresentaram anormalidade na sua distribuição, considerando os três parâmetros em estudo. Os coeficientes de determinação obtidos para 3TC, AZT e NVP (Tabela 3), respectivamente, sugerem que 99,68; 99,78 e 99,78\% da variação total em torno das médias são explicadas pela regressão, restando 0,$32 ; 0,22$ e $0,22 \%$ explicados pelos resíduos. Portanto, o método é linear nas concentrações propostas.

\section{Precisão e exatidão}

O método apresentou-se preciso nos dois níveis analisados. $\mathrm{Na}$ repetitividade, as seis amostras autênticas com concentração de $100 \%$ (Tabela 4), apresentaram desvio padrão relativo (RSD) para $3 T C$, AZT e NVP inferiores a $2 \%$. Para a precisão intermediária (Tabela 5), os resultados entre dias e analistas diferentes não evidenciaram diferença estatisticamente significativa entre analistas e dias, empregando-se o teste t de Student. Como resultados para o $t$ calculado, têm-se no $1^{\circ}$ dia e para analistas diferentes 0,$911 ; 1,697$ e 1,277 ; já no $2^{\circ}$ dia, os valores foram de 0,$040 ; 0,437$ e 1,373 para

Tabela 2. Análise estatística das variações testadas para verificação da robustez do método analítico validado para doseamento simultâneo de 3TC, AZT e NVP

Análise lamivudina $(45 \mu \mathrm{g} / \mathrm{mL}) \quad$ zidovudina $(90 \mu \mathrm{g} / \mathrm{mL}) \quad$ nevirapina $(150 \mu \mathrm{g} / \mathrm{mL})$

estatística

Proporção de fase móvel (\%)

\begin{tabular}{lccccccccc}
\hline & $58: 42$ & $60: 40$ & $62: 38$ & $58: 42$ & $60: 40$ & $62: 38$ & $58: 42$ & $60: 40$ & $62: 38$ \\
Média & 46,83 & 46,59 & 46,74 & 93,17 & 93,13 & 93,14 & 63,48 & 62,66 & 63,29 \\
RSD (\%) & 1,56 & 1,29 & 1,59 & 0,50 & 1,24 & 0,44 & & 1,62 & 0,94 \\
F cal & & 0,137 & & & 0,003 & & & 1,01 & \\
F tab & & & & & 3,885 & & & &
\end{tabular}

\begin{tabular}{|c|c|c|c|c|c|c|c|c|c|}
\hline & \multicolumn{9}{|c|}{ Fluxo de fase móvel (mL/min) } \\
\hline & 0,99 & 1,00 & 1,01 & 0,99 & 1,00 & 1,01 & 0,99 & 1,00 & 1,01 \\
\hline Média & 44,77 & 44,04 & 44,18 & 89,50 & 89,30 & 88,41 & 59,72 & 58,97 & 59,10 \\
\hline $\operatorname{RSD}(\%)$ & 1,69 & 0,56 & 0,73 & 1,11 & 0,49 & 1,00 & 0,52 & 1,10 & 1,49 \\
\hline F cal & & 3,041 & & & 3,347 & & & 1,837 & \\
\hline $\mathrm{F}$ tab & & & & & 3,885 & & & & \\
\hline
\end{tabular}

\begin{tabular}{|c|c|c|c|c|c|c|c|c|c|}
\hline & \multicolumn{9}{|c|}{ Temperatura do forno da coluna $\left({ }^{\circ} \mathrm{C}\right)$} \\
\hline & 28 & 30 & 32 & 28 & 30 & 32 & 28 & 30 & 32 \\
\hline Média & 45,04 & 44,53 & 44,97 & 90,48 & 90,21 & 90,83 & 61,09 & 60,66 & 61,18 \\
\hline $\operatorname{RSD}(\%)$ & 1,10 & 0,85 & 1,61 & 0,61 & 0,62 & 0,64 & 1,10 & 0,47 & 0,90 \\
\hline F cal & & 1,229 & & & 1,554 & & & 1,388 & \\
\hline $\mathrm{F}$ tab & & & & & 3,885 & & & & \\
\hline
\end{tabular}

\begin{tabular}{|c|c|c|c|c|c|c|c|c|c|}
\hline & \multicolumn{9}{|c|}{ Tempo de sonicação da amostra (min) } \\
\hline & 15 & 20 & 25 & 15 & 20 & 25 & 15 & 20 & 25 \\
\hline Média & 44,25 & 44,04 & 44,20 & 89,24 & 87,83 & 88,20 & 59,46 & 59,02 & 59,39 \\
\hline $\operatorname{RSD}(\%)$ & 1,19 & 0,56 & 1,08 & 1,13 & 1,28 & 1,17 & 0,84 & 1,01 & 0,85 \\
\hline F cal & & 0,312 & & & 2,321 & & & 0,978 & \\
\hline \multirow[t]{3}{*}{ F tab } & & & & & 3,885 & & & & \\
\hline & \multicolumn{9}{|c|}{ Diferentes lotes da coluna cromatográfica } \\
\hline & 2289547 & 160140 & 3307383 & 2289547 & 160140 & 3307383 & 2289547 & 160140 & 3307383 \\
\hline Média & 44,02 & 44,36 & 44,29 & 89,23 & 89,52 & 88,81 & 60,25 & 59,97 & 60,06 \\
\hline RSD (\%) & 1,48 & 1,55 & 0,74 & 0,85 & 0,82 & 0,70 & 1,10 & 1,01 & 0,84 \\
\hline F cal & & 0,461 & & & 2,818 & & & 0,284 & \\
\hline $\mathrm{F}$ tab & & & & & 3,885 & & & & \\
\hline
\end{tabular}


Tabela 3. Resultados da linearidade obtidos a partir de três curvas autênticas dos fármacos associados (lamivudina, zidovudina e nevirapina) nas condições do método validado

\begin{tabular}{lccr}
\hline & lamivudina & zidovudina & nevirapina \\
\hline IC $( \pm \mathrm{DP})$ & 52812,31 & 42449,57 & 32655,38 \\
& $( \pm 2205,36)$ & $( \pm 1470,17)$ & $( \pm 1117,99)$ \\
Coeficiente & 119560,00 & 164932,90 & 47994,81 \\
linear $( \pm \mathrm{DP})$ & $( \pm 114832,30)$ & $( \pm 153102,60)$ & $( \pm 77617,68)$ \\
$\mathrm{R}^{2}$ & 0,9968 & 0,9978 & 0,9978 \\
Intervalo & $30-75$ & $60-150$ & $40-100$ \\
& $\mu \mathrm{g} / \mathrm{mL}$ & $\mu \mathrm{g} / \mathrm{mL}$ & $\mu \mathrm{g} / \mathrm{mL}$ \\
$\mathrm{LD}$ & 1,11 & 1,54 & 2,00 \\
& $\mu \mathrm{g} / \mathrm{mL}$ & $\mu \mathrm{g} / \mathrm{mL}$ & $\mu \mathrm{g} / \mathrm{mL}$ \\
LQ & 1,69 & 2,33 & 3,03 \\
& $\mu \mathrm{g} / \mathrm{mL}$ & $\mu \mathrm{g} / \mathrm{mL}$ & $\mu \mathrm{g} / \mathrm{mL}$ \\
F calculado & 3,705 & 4,277 & 2,919 \\
F tabelado & 5,218 & 5,218 & 5,128 \\
\hline
\end{tabular}

Tabela 4. Resultados analíticos da repetitividade (precisão intradia) do método validado

\begin{tabular}{lcccccccc}
\hline & \multicolumn{4}{c}{ Concentração } & \multicolumn{4}{c}{ Média \%RSD } \\
& 1 & 2 & 3 & 4 & 5 & 6 & & \\
\hline 3TC & 44,79 & 44,81 & 43,95 & 43,36 & 44,28 & 44,79 & 44,33 & 1,33 \\
AZT & 90,18 & 90,02 & 89,68 & 89,07 & 90,00 & 91,15 & 90,02 & 0,76 \\
NVP & 61,44 & 60,48 & 60,30 & 60,73 & 60,75 & 61,04 & 60,79 & 0,67 \\
\hline
\end{tabular}

3TC, AZT e NVP, respectivamente. Todos os resultados se mostraram inferiores ao $t$ tabelado de 2,306; confirmando com $95 \%$ de confiança que o método é preciso, por não apresentar diferenças estatisticamente significativas entre analistas e entre dias.

$\mathrm{Na}$ exatidão, os resultados para o $t$ calculado referente à concentração mínima considerada de $66 \%$ para a concentração média de $100 \%$, e para a concentração máxima referente a $166 \%$ estão descritos na Tabela 6. Estes resultados quando comparados com o $t$ tabelado de 2,776 com $95 \%$ de confiança se apresentaram inferiores, demonstrando que o método desenvolvido é exato, já que não
Tabela 6. Resultados do tratamento estatístico por teste $t$ de Student para verificação da exatidão do método

\begin{tabular}{llcc}
\hline Concentração & & $\mathrm{t}$ calculado & $\mathrm{t}$ tabelado \\
\hline \multirow{3}{*}{$66 \%$} & 3TC & 0,449 & \\
& AZT & 0,175 & \\
$100 \%$ & NVP & 0,815 & \\
& $3 \mathrm{TC}$ & 0,908 & \\
& AZT & 0,850 & 2,776 \\
$166 \%$ & NVP & 1,771 & \\
& 3TC & 1,353 & \\
& AZT & 1,554 & \\
\hline
\end{tabular}

foram evidenciadas diferenças estatisticamente significativas entre os valores obtidos e os esperados.

\section{Especificidade}

O método proposto demonstrou ser seletivo e específico, não sendo afetado pelos excipientes utilizados no processo de fabricação do comprimido revestido, o que pôde ser confirmado pela ausência de absorvâncias nos tempos de retenção dos picos referentes aos três fármacos (Figura 3).

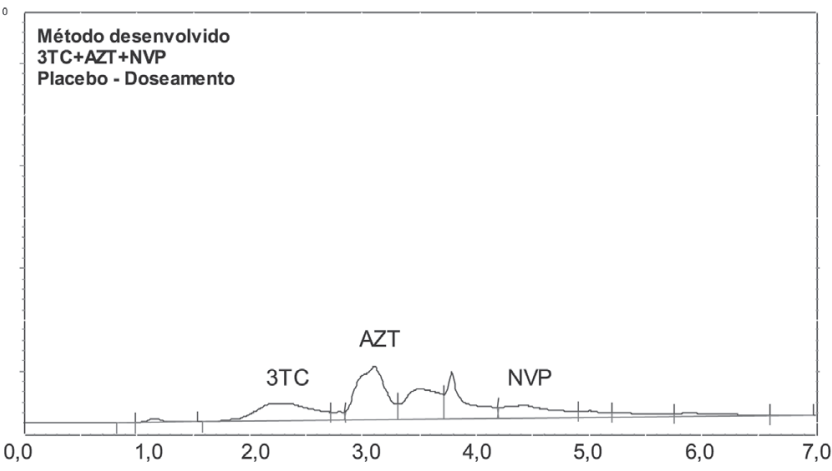

Figura 3. Cromatograma da especificidade do método com comprimido revestido placebo

Tabela 5. Resultados do tratamento estatístico por teste t de Student para verificação da precisão do método validado entre analistas e dias diferentes

\begin{tabular}{|c|c|c|c|c|c|c|c|c|c|c|}
\hline & & Dia I & & & Dia II & & & & & \\
\hline & $3 \mathrm{TC}$ & $\mathrm{AZT}$ & NVP & $3 \mathrm{TC}$ & AZT & NVP & & & & \\
\hline & & & ta I & & & & & Analist & $\mathrm{I}-\mathrm{Di}$ & I e II \\
\hline & & & & & & & & $3 \mathrm{TC}$ & $\mathrm{AZT}$ & NVP \\
\hline Média & 44,07 & 90,21 & 60,58 & 44,29 & 90,13 & 60,41 & t calculado & 0,799 & 0,169 & 0,431 \\
\hline RSD \% & 1,18 & 0,62 & 0,93 & 0,74 & 1,00 & 1,12 & t tabelado & & 2,306 & \\
\hline & & & ta II & & & & & Analista & II - Di & a I e II \\
\hline & & & & & & & & $3 \mathrm{TC}$ & AZT & NVP \\
\hline Média & 40,30 & 90,84 & 61,09 & 40,28 & 90,35 & 60,86 & t calculado & 0,088 & 1,199 & 0,688 \\
\hline RSD \% & 0,49 & 0,68 & 1,13 & 1,03 & 0,75 & 0,46 & $\mathrm{t}$ tabelado & & 2,306 & \\
\hline & & $\begin{array}{c}\text { Dia I } \\
\text { alistas I }\end{array}$ & & & $\begin{array}{l}\text { Dia II } \\
\text { listas I }\end{array}$ & & & & & \\
\hline t calculado & 0,911 & 1,697 & 1,277 & 0,040 & 0,437 & 1,373 & & & & \\
\hline t tabelado & & & & & & & & & & \\
\hline
\end{tabular}




\section{CONCLUSÃO}

O método descrito neste trabalho foi desenvolvido a fim de se disponibilizar um procedimento analítico para quantificação desta associação de fármacos antiretrovirais em comprimidos revestidos dose-fixa-combinada, haja vista a inexistência de métodos oficiais destinados a este doseamento. É um método simples, apresentando confiabilidade e segurança necessárias em procedimentos analíticos. Os parâmetros verificados garantiram que ele é robusto, exato, preciso e específico para a quantificação da forma farmacêutica contendo a associação de lamivudina, zidovudina e nevirapina, apresentando-se, portanto, validado conforme a RE 899/2003 (ANVISA) e sendo recomendado para a rotina de análises de controle de qualidade na indústria farmacêutica, atendendo às Boas Práticas de Laboratório.

\section{REFERÊNCIAS}

1. Panchagnula, R.; Khandavilli, S.; Kapoor, N.; Anal. Chim. Acta 2006, 570, 41.

2. Tidwell, R. R.; Pereira, A. S.; J. Chromatogr., B: Anal. Technol. Biomed. Life Sci. 2001, 764, 327.
3. Matioli, G.; Sommer, W. A.; Valentini, S. R.; Acta Scientiarum. Health Sci. 2004, 16, 357.

4. Jardim, I. C. S. F.; Collins, C. H.; Bottoli, C. B. G.; Ribani, M.; Melo, L. F. C.; Quim. Nova 2004, 27, 771.

5. Kenney, K. B.; Wring, S. A.; Carr, R. M.; Wells, G. N.; Dunn, J. A.; J. Pharm. Biomed. Anal. 2000, 22, 967.

6. Rodriguez, J. F.; Rodriguez, J. L.; Santana, J.; Garcia, H.; Rosário, O.; Antimicrob. Agents Chemother. 2000, 44, 3097.

7. Doerge, D. R.; Beland, F. A.; von Tungeln, L. S.; Wulliams, L. D.; J. Chromatogr., B: Anal. Technol. Biomed. Life Sci. 2003, 798, 55.

8. Mahadik, K. R.; Paradkar, A. R.; Agrawal, H.; Kaul, M.; Talanta 2004 $62,843$.

9. Brasil. Resolução RE nº899 de 29/5/2003; Diário Oficial da União, Brasília, DF, 02/06/2003, seção 1 - Agência Nacional de Vigilância Sanitária (ANVISA) aprova o Guia para validação de métodos analíticos e bioanalíticos.

10. Farmacopéia Brasileira, IV ed., Atheneu: São Paulo, 2003.

11. United States Pharmacopoeia, 29 $9^{\text {th }}$ ed., United States Pharmacopoeia Convention: Rockville, 2006.

12. Snyder, L. R.; Kirkland, J. J.; Glajch, J. L.; Practical HPLC Method Development, $2^{\text {nd }}$ ed., John Wiley \& Sons: New York, 1997.

13. Kedor-Hackmann, E. R. M.; Prado, M. S. A.; Steppe, M.; Santoro, M. I. R. M.; Rev. Bras. de Farmácia 2002, 83, 69.

14. Cass, Q. B.; Degani, A. L.; Desenvolvimento de métodos por HPLC: fundamentos, estratégias e validação, UFSCAR: São Carlos, 2001. 